Research Article

\title{
Experimental Study of the Development of Soil Microstructure under the Electroosmosis Dewatering Process
}

\author{
Yimin Liu $\mathbb{D},,^{1,2}$ Lingwei Zheng $\mathbb{D}^{3}{ }^{3}$ and Shaohua Rao $^{2}$ \\ ${ }^{1}$ College of Civil and Transportation Engineering, Shenzhen University, Shenzhen, China \\ ${ }^{2}$ Shenzhen Talents Housing Group Corporation. Limited, Shenzhen, China \\ ${ }^{3}$ Research Center of Coastal and Urban Geotechnical Engineering, Zhejiang University, Hangzhou, China \\ Correspondence should be addressed to Yimin Liu; yiminliu@zju.edu.cn
}

Received 17 November 2020; Revised 5 January 2021; Accepted 19 January 2021; Published 1 February 2021

Academic Editor: Ştefan Țălu

Copyright (C) 2021 Yimin Liu et al. This is an open access article distributed under the Creative Commons Attribution License, which permits unrestricted use, distribution, and reproduction in any medium, provided the original work is properly cited.

Several laboratory experiments using scanning electron microscopy and mercury intrusion porosimetry were conducted to study the development of soil microstructure during electroosmosis dewatering process. The test results indicate that the moisture content in different treating areas shows remarkable temporal difference; the reasons could be attributed to the distance to the drainage outlets and the treatment duration. On a microscopic level, the affected pore sizes are mainly $0.01-1$ and $1-10 \mu \mathrm{m}$, and their proportions start to vary when the moisture content reaches the liquid limit. The total volume for pores in anodic soil decreases nearly $50 \%$ after the first $20 \%$ of total drainage water is exported and is not linearly related to the amount of discharged water. The surface of the soils becomes smoother, and clay particle connection changes from edge-to-edge to face-to-face. Pores are hard to be observed at the end of the process.

\section{Introduction}

In recent years, land reclamation in southeastern China is widely used, and the need for ground treatment of marine muck is urgent $[1,2]$. In this kind of dredger fill, ground improvement methods such as surcharge preloading or vacuum preloading are not satisfactory due to long treatment duration or low economic efficiency. These shortcomings could be overcome with electroosmosis (EO) treatments, and successful case records are reported [3-5]. This method is capable of accelerating the dewatering process of pore water and consolidation of soils to enhance the soil foundation, especially in soft soils with high moisture content, low shear strength, and low hydraulic conductivity.

Researchers are usually concerned with the critical factors that influence the EO dewatering process, such as electrode materials and arrangements [6-8], electric gradients $[9,10]$, electric resistances on the soil-electrode surface, and soil properties [11, 12]. On the contrary, EO treatments are frequently combined with conventional techniques such as vacuum preloading [13], surcharge preloading [14], and chemical grouting [15]. In recent years, a large number of theoretical and numerical models have been established to reveal the mechanism of the process. These models consider two-dimensional electroosmotic flow [16-18], electric charge accumulation [19], gas generation $[20,21]$, the constitutive relationship of unsaturated soils [22], large deformation $[23,24]$, and the coupled effects of multiple physical fields with the help of the finite element method or finite difference method.

Previous studies have supplied much information about electrokinetic stabilization, but it is still far from totally understanding the mechanism of the EO treatment. Since macroscopic behaviors and physical properties of soil are mostly dominated by microscopic characteristics, several studies investigated the microscopic level of electrokinetic treatments. For instance, Hang [25] concluded that soil particles became smoother, and clays became more intense and explained surface settlement due to floc structure disruption and the decreased draining rate in the late stages of the process with the help of scanning electron microscopy. $\mathrm{Li}$ [26] found the specific area and pore size of soil modified approach using hydroxyl-aluminum solution for electrolyte 
decrease, resulting in an increase in the internal friction angle. However, further studies on the microscopic characteristics and more precise data are still necessary.

This paper investigates the microstructure of the soil during a single electrokinetic dewatering process, including pore size distribution and particle surface characteristics. We preliminarily focus on the relationship between water migration during the treatment and the pore size distribution and other microstructural properties. In this paper, several EO dewatering model tests were conducted, followed by scanning electron microscopy and mercury intrusion tests. The test details and results are discussed below.

\section{Method}

\subsection{Material and Test Procedures}

2.1.1. Soil Sample. The soil samples were extracted from a foundation project located at Guangdehu North Road in Ningbo, Zhejiang Province, China, at a depth of 6-8 m. The basic physical properties of the undisturbed soil are listed in Table 1, and the particle size distribution of the soil is shown in Figure 1. Based on the mean particle diameter $(10.1 \mu \mathrm{m})$ and the other typical physical parameters in Table 1, the soil can be classified as mucky soil, which usually has low shear strength, has poor hydraulic conductivity, has high void ratio and is widespread around southeastern China.

2.1.2. Testing Apparatus. The apparatus is a cuboid Plexiglass tank combined with DC power, multimeter, and water collector. As shown in Figure 2, the inner geometry of Plexiglass is $300 \mathrm{~mm}$ in length, $250 \mathrm{~mm}$ in width, and $230 \mathrm{~mm}$ in height. A cover plate is put on the top of the box, reducing the evaporation near the surface of the soil due to the temperature increase during the electroosmosis process. Considering the effective electrical conductivity, corrosion resistance, and economic efficiency, stainless steel electrodes are adopted. The perforated cathodes are wrapped with geotechnical cloth, and there are $10 \mathrm{~mm}$ diameter round holes every $30 \mathrm{~mm}$ on the cathodes so that the drainage water can drain out of the samples without fine soil particles. The distance between anodes and cathodes is $260 \mathrm{~mm}$.

2.1.3. Test Procedures. The undisturbed soil was dried at $105^{\circ} \mathrm{C}$ for 24 hours and then ground into powder to obtain suitable remolded soil for experiments. The powder was sifted through a $0.25 \mathrm{~mm}$ diameter griddle and mixed thoroughly with distilled water into a slurry. Moisture content of 1.5 to 1.6 times the liquid limit [27] was sufficient to form a workable slurry, for example, $70 \%$ moisture content in this paper. The sample was then poured into the Plexiglass tank. Each slurry layer was $40 \mathrm{~mm}$ thick and tapped to eject air bubbles. The height of the slurry sample was $200 \mathrm{~mm}$. We let the slurry stand for 24 hours to obtain an isotropic sample and allow water drainage due to gravity. According to the test results, the water drainage due to gravity was close to zero and negligible.
TABle 1: Physical index and mineral composition.

\begin{tabular}{lcc}
\hline Physical properties & & \\
Parameters & Units & Value \\
\hline & $<0.005$ & $24.53 \%$ \\
Particle diameters $(\mathrm{mm})$ & $0.005-0.075$ & $75.49 \%$ \\
& $\mathrm{~d}(0.5)(\mathrm{mm})$ & 0.01 \\
Specific surface area & $\mathrm{m}^{2} / \mathrm{g}$ & 1.09 \\
Bulk density & $\mathrm{g} / \mathrm{cm}^{3}$ & 1.70 \\
Natural water content & - & $46.16 \%$ \\
Plastic limit & - & $30.7 \%$ \\
Liquid limit & - & $53.1 \%$ \\
Plasticity index & - & 22.4 \\
Specific gravity & - & 2.61 \\
$\mathrm{Void}$ ratio & - & 1.244 \\
$\mathrm{pH}$ & - & 7.3 \\
\hline $\mathrm{Mineral} \mathrm{composition}_{\mathrm{SiO}}$ & & \\
$\mathrm{Al}_{2} \mathrm{O}_{3}$ & - & $59.34 \%$ \\
$\mathrm{Fe}_{2} \mathrm{O}_{3}$ & - & $18.43 \%$ \\
$\mathrm{~K}_{2} \mathrm{O}$ & - & $8.50 \%$ \\
$\mathrm{MgO}$ & - & $3.93 \%$ \\
\hline
\end{tabular}

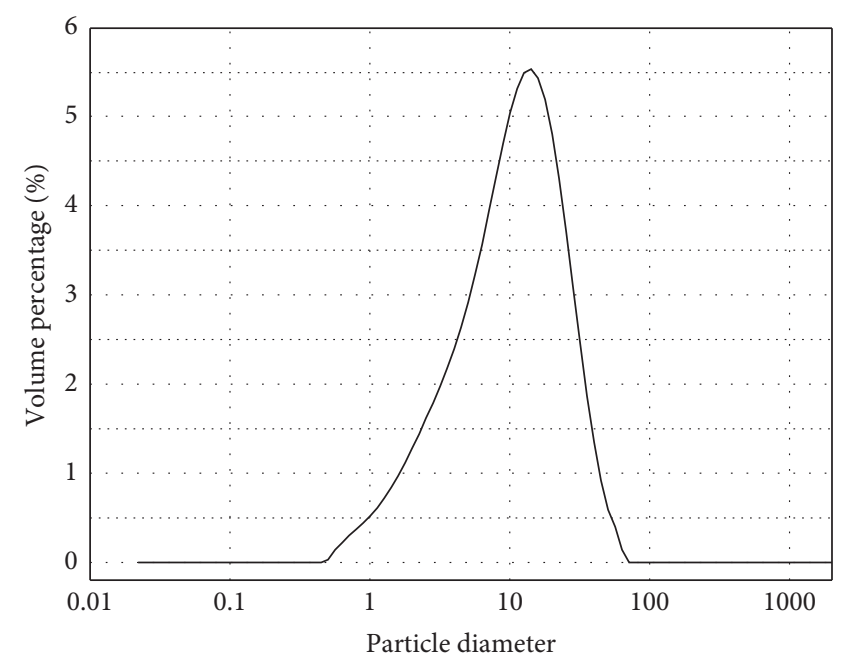

Figure 1: Particle size distribution.

The voltage gradient was set to $1.0 \mathrm{~V} / \mathrm{cm}$. The treatment for the initial calibration test lasted for 48 hours, and the total drainage amount was measured to be $\mathrm{W}$ by volume. Several tests were performed to study the evolution of soft soil microstructure during the EO process. Their total drainage amounts were set at $0,0.2 \mathrm{~W}, 0.4 \mathrm{~W}, 0.6 \mathrm{~W}$, and $0.8 \mathrm{~W}$, respectively, and the duration time was measured. EO1 is the undisturbed soil sample, and EO6 is the calibration test. The details are given in Table 2 .

\subsection{Scanning Electron Microscopy and Mercury Intrusion} Porosimetry. When the total drainage amounts reached the preset value, the power supply was cut off immediately, and the samples (each about $1 \mathrm{~cm}^{3}$ cube; 9 samples for SEM tests and 15 samples for MIP tests) were removed at the labeled locations for further studies. The labeled locations are point A (anode), NA (near anode), M (middle), NC (near 


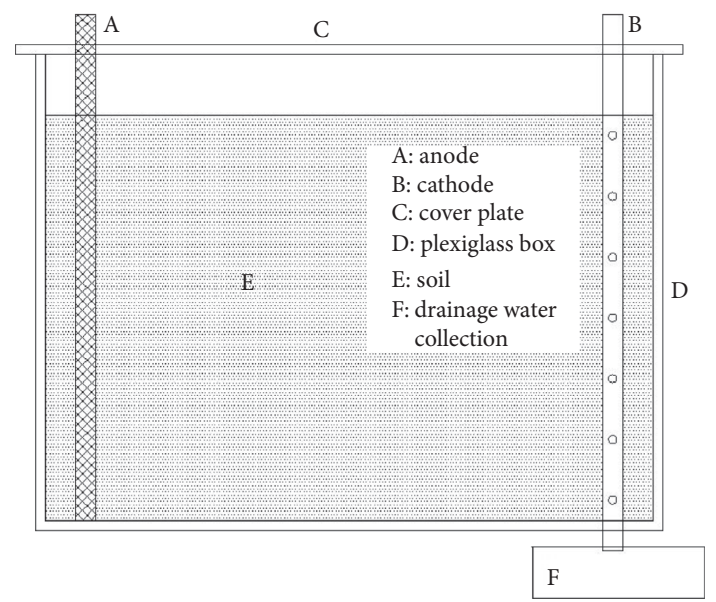

(a)

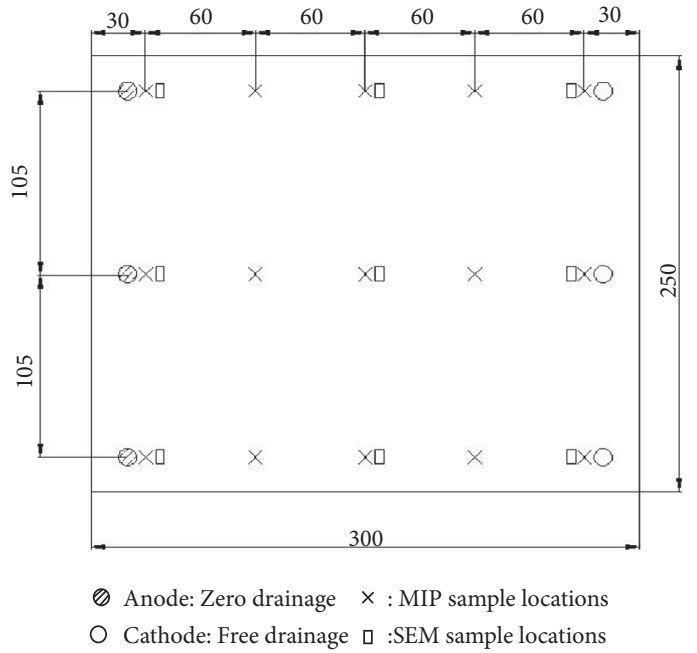

(b)

Figure 2: (a) Testing apparatus diagrams. (b) Sample locations.

TABle 2: Details of the EO tests.

\begin{tabular}{lccccc}
\hline & Voltage gradient $(\mathrm{V} / \mathrm{cm})$ & Drainage water $(\mathrm{mL})$ & Treat time $(\mathrm{h})$ & SEM samples & MIP samples \\
\hline EO1 & 0 & 0 & 0 & 3 & 3 \\
EO2 & 1.0 & $0.2 \mathrm{~W}$ & 4.5 & 9.0 & 9 \\
EO3 & 1.0 & $0.4 \mathrm{~W}$ & 16.0 & 9 & 15 \\
EO4 & 1.0 & $0.6 \mathrm{~W}$ & 25.5 & 9 & 15 \\
EO5 & 1.0 & $0.8 \mathrm{~W}$ & 48.0 & 15 \\
EO6 & 1.0 & $\mathrm{~W}$ & & & 9 \\
\hline
\end{tabular}

cathode), and C (cathode) from the anode to the cathode; the lateral distance between each point is $60 \mathrm{~mm}$ as shown in Figure 2(b)).

Soil samples desiccation is necessary according to the requirements of the SEM and MIP tests. It is noteworthy that the water content is vital to the structure of the soil. To maintain the inner microstructure of the soil samples after the drying process, the vacuum freeze drying method was employed instead of air drying or oven drying [28], due to its small geometrical variation before and after the dehydrating process. Chai [29] pointed out that the volume shrinkage ratios by air drying and freeze drying for kaolin, illite, and montmorillonite are $14.8 \%$ and $1.1 \%, 23.1 \%$ and $2.4 \%$, and $98.5 \%$ and $4.7 \%$, respectively; shrinkage ratios in length for the mentioned minerals are $5.6 \%$ and $0.4 \%, 10.1 \%$ and $0.1 \%$, and $84.5 \%$ and $2.1 \%$, respectively.

It is reported that pore water is transferred to amorphous ice with little volume change at the extreme low temperature. The samples were immersed into liquid nitrogen until sufficiently cooled and then put into the cold trap of a lyophilizer with a vacuum pump at the temperature of $-50^{\circ} \mathrm{C}$ for 24 hours, as shown in Figure 3.

Scanning electron microscope (SIRION-100, Field Electron and Ion Company, Netherlands) was used to observe the soil samples surface. The microscopic images can provide information about the connections between soil particles and morphological characterization parameters through image analysis software.

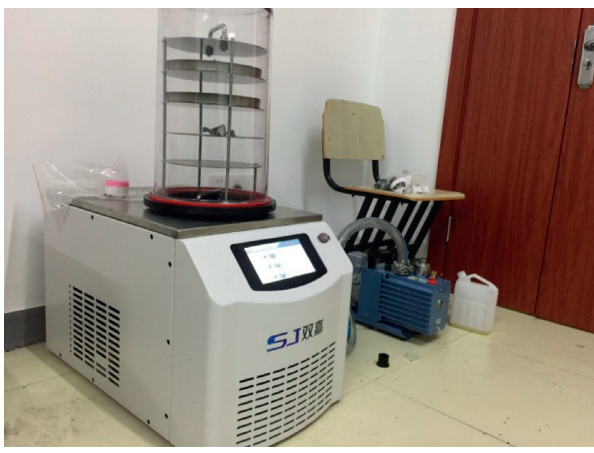

FIgURE 3: Lyophilizer with a vacuum pump.

The mercury intrusion porosimetry (MIP) can determine the pore size distribution. According to Washburn's theory [30], an external force must be applied to neutralize the surface tension between mercury and soil particles so that mercury can be pushed into the pore. The external force is

$$
p=\frac{2 \sigma \cos \theta}{r}
$$

$\sigma$ is the surface tension for mercury, $0.484 \mathrm{~N} / \mathrm{m} ; \theta$ is the contact angle between two phases, $130^{\circ}$ in this case; and $r$ is the radius of the pore. The pore size distribution can be calculated by measuring the applied pressure and the volume of the pressed-in mercury. 


\section{Results and Discussion}

3.1. Electroosmosis Tests. Figure 4 illustrates the cumulative drainage water and the current in the EO6 test. On the basis of the final amount for EO6, which is $2140.8 \mathrm{~mL}$, the break point for EO1 to EO5 was determined to be $0,428.1,856.3$, 1284.5, and $1712.6 \mathrm{~mL}$, respectively. Treatment time for these tests is listed in Table 2 according to the actual experiments.

The drainage rate was fast in the early stages, reached its maximum value at 5-6 hours, $111.7 \mathrm{~mL} /$ hour, and decreased rapidly after that. The current reached its peak value $0.706 \mathrm{~A}$ at 4-5 hours and remained essentially steady until hour 9. The current dropped along with the treatment time, and the final current was $0.366 \mathrm{~A}$ at 48 hours. In the last 3 hours, the drainage amount was $48.7 \mathrm{~mL}$, only $2.2 \%$ of the total volume, and the EO treatment was deemed to be finished [31].

The moisture contents of different phases are shown in Figures 5 and 6 . Overall, the longer the treatment duration is, the lower the average water content is. The moisture content remained unchanged in EO1 after 48 hours. Soil samples in the EO6 have the lowest average water content because they have the longest treatment time; the moisture content of anode soil and near-anode soil was $41.38 \%$ and $38.51 \%$, respectively. Focusing on the first few hours of treatment, after the EO2 treatment $(4.5 \mathrm{~h})$, moisture content changed little $(70.16 \%$ to $69.02 \%)$, while the variation in cathode (C) soil samples was $17.20 \%$, from $70.16 \%$ to $52.96 \%$. This is quite different compared with the final results of EO treatment. The reasons are explained below.

Figure 6 shows the rule of pore water migration precisely. In cathode (C) samples, despite the large variation in the first few hours, the moisture shows little downward trend in subsequent treatments, and it even increases to $58.08 \%$, much higher than the liquid limit after the whole process. In anode (A) samples, the moisture content declined at the very beginning but changes little after EO2. In other words, the energy consumption at the soil between A and NA during $\mathrm{EO} 2$ to EO6 causes little drainage, and this is not economically efficient in practical engineering. Some relevant research has been done to save unnecessary energy consumption. Liu [32] reported an anode follow-up technique that can promote the effectiveness of EO treatment and reduce the resistance of the anodic region. The paper failed to investigate the energy consumption during the process, but the reduction in the resistance of the anodic region will increase the effective potential and reduce the joule heat generated in anodic soil.

As for the samples (NA, M, and NC) in the middle of the tank, the moisture content declines with time. The differences among them are the moment when the water content drops quickly and the final water content. The biggest moisture drop in the NA samples happened between EO3 and $\mathrm{EO} 4$, from $67.51 \%$ to $49.20 \%$, an $18.31 \%$ drop; in $\mathrm{M}$ samples, it happened between EO4 and EO5, from $68.68 \%$ to $52.20 \%$; and in NC samples, it happened between EO4 and EO5, from $61.28 \%$ to $48.34 \%$.

When the EO begins, all the pore water begins to move toward the cathode where drainage is allowed. The water in the cathode area soil first starts to discharge under external

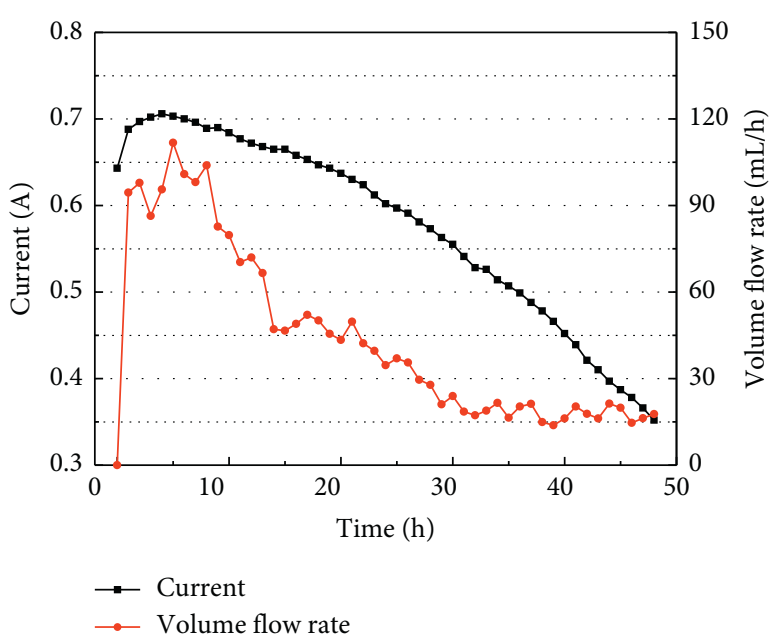

Figure 4: Total drainage water vs. current in the soils.

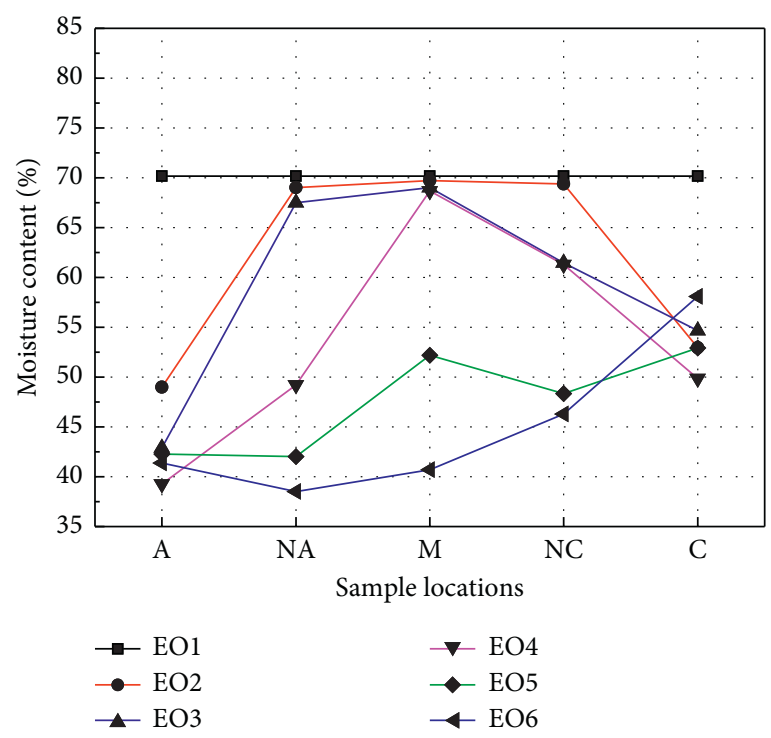

Figure 5: Moisture contents at different times.

electrical force; at this time, the drainage water from the anode area fails to reach the cathode area, which leads to an apparent water reduction in cathode soil. However, when drainage water from the anode and near-anode area soil arrives at the cathode, the moisture content increases. The moisture content in different areas shows a remarkable temporal difference, and the reasons could be attributed to the distance to the drainage outlets and the treatment duration.

\section{2. $M I P$}

3.2.1. Anodic Soils. Pore size distribution of remolded soil (EO1 test) is illustrated in Figure 7. The area between the curve and the $X$-axis represents the total volume of the pores. The curve has two major peaks, $3 \mu \mathrm{m}$ higher peak and $0.1 \mu \mathrm{m}$ lower peak. The main concentration is between 0.01 and $10 \mu \mathrm{m}$; the volume of pore diameters is $26.71 \%$ between 0.01 and $1 \mu \mathrm{m}$ and $70.01 \%$ between 1 and $10 \mu \mathrm{m}$. 


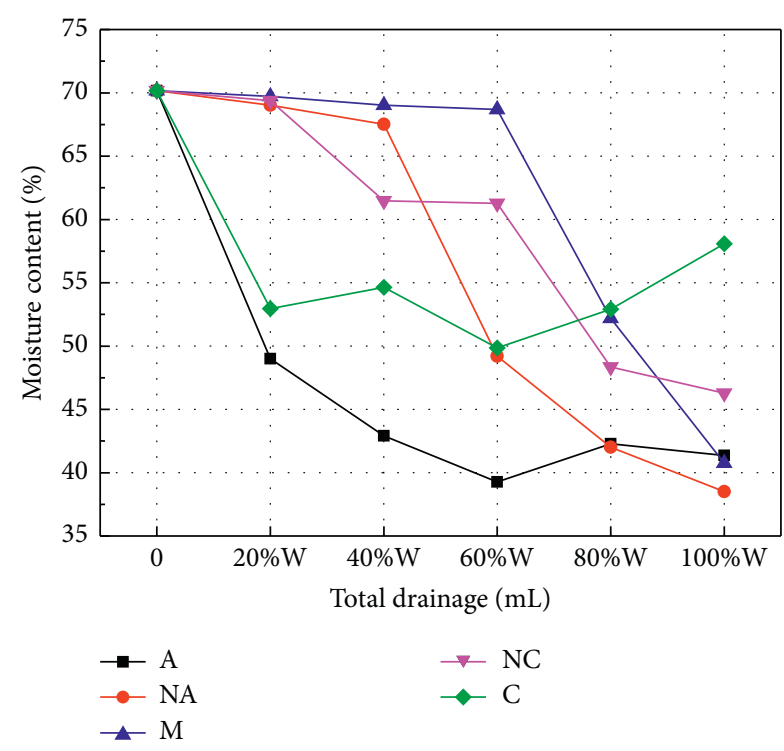

Figure 6: Moisture content at different points.

The influence of EO treatments on pore size distribution is mainly focused on pores with $0.01-1 \mu \mathrm{m}$ and $1-10 \mu \mathrm{m}$ diameters according to Figure 7 and Table 3. Griffiths and Joshi [33] pointed out that pores whose diameter is less than $0.01 \mu \mathrm{m}$ are independent of the matric suction or stress. The lower limit in this experiment indicates that EO treatment has no significant impact on the pores whose diameters are less than $0.01 \mu \mathrm{m}$. This result is the same as Griffiths and Joshi.

In the anodic area, after EO treatments, the curves each have only one obvious peak, and the peak moves toward the lower left to around $1 \mu \mathrm{m}$ as shown in Figure 7. It can be seen that abundant pores with $1-10 \mu \mathrm{m}$ diameters rupture into pores of $0.01 \sim 1 \mu \mathrm{m}$. This is because when the external electric field is applied to the soil where drainage is allowed at the cathode, negative pore pressures are generated throughout the soil [34]. Soil skeleton is crushed under the effective stress, and the space of the soil aggregation is invaded by the crushed soil particles. As a consequence, the volume of pores with $0.01-1 \mu \mathrm{m}$ diameter increases, whereas that of pores with $1-10 \mu \mathrm{m}$ diameter decreases.

The total volume of the pores is compressed under the effective stress, and it can be seen in Figure 8. The original remolded soil has $0.5909 \mathrm{~mL} / \mathrm{g}$, while it is $0.2930 \mathrm{~mL} / \mathrm{g}$ in EO6. The variation between $\mathrm{EO} 1$ and $\mathrm{EO} 2$ is the most significant with a shrinkage range of $48.54 \%$. Although the drainage water increments are equivalent in EO3 EO6, the shrinkage increments are decreasing, from $17 \%$ to $5 \%$. The shrinkage of the pore's total volume is not linearly related to the discharged water and is nearly half after the first $20 \%$ of drained water is ejected. The different pore diameter volumes throughout the soils are listed in Table 3, and their percentages are shown in Figure 9.

During the soil dewatering process, water in the large spaces between aggregates would drain out of the pore when the matric suction is relatively low. With the pore water draining and the matric suction growing, pores begin to

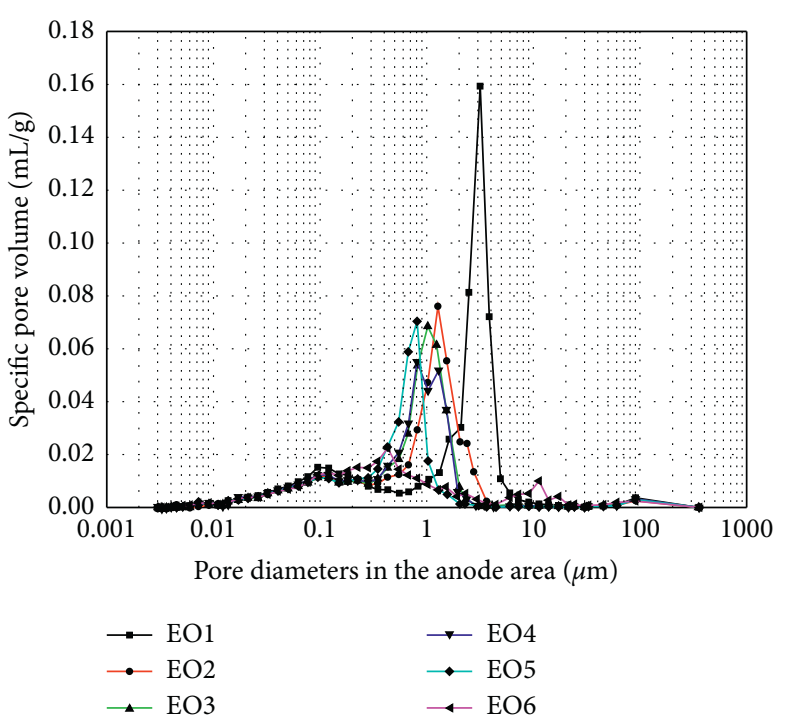

Figure 7: Pore diameters in the anode area.

shrink, leading to a decreased pore size. In the anodic area, as shown in Figure 6, although the moisture content varies little between EO3 and EO6, the percentage of pores with a diameter between 0.01 and $1 \mu \mathrm{m}$ increases nearly linearly with the drained water, whereas the pores with diameter between 1 and $10 \mu \mathrm{m}$ almost vanish after the process. The proportion of pores with a diameter between 0.01 and $1 \mu \mathrm{m}$ varies from $27.8 \%$ to $90.4 \%$, and pores with a diameter of $1-10 \mu \mathrm{m}$ vary from $70.0 \%$ to $5.9 \%$. Pore size is not linearly related to the moisture content in the anodic area. The reason for this situation may be the water content of the soil, and it will be discussed in the following section.

3.2.2. Cathodic Soils. Pore size distribution in the cathodic area is shown in Figures 10 and 11. As shown in Figure 10, pores with large diameter $(9.0-24.2 \mu \mathrm{m})$ appear in the soil samples after the entire EO treatment (EO6). These pores do not exist in the untreated samples. This might be the result of increasing the moisture content in the cathodic soil at the late stages of the EO dewatering process, as shown in Figure 6 . In the late stages of the dewatering process, the drainage path on the cathodic electrodes might be blocked by the fine soil particles carried by the drained water, and the drainage condition is not clear enough. As a result, the pore water is gathered at the cathodic area, thus increasing the moisture content (58.08\%, higher than the liquid limit), and the space among the soil aggregates is expanded by the pore water.

Figure 11 illustrates the total volume of soil samples in different dewatering stages. The total volume increased from $0.4047 \mathrm{~mL} / \mathrm{g}$ in EO3 to $0.4353 \mathrm{~mL} / \mathrm{g}$ in EO6. The increment of the total volume of the pores at late stage of the dewatering process supports the argument. When the moisture content reaches the liquid limit, no structural stress exists between the soil particles and the shear strength is zero. Under this condition, the pore water will expand the space between soil particles, resulting in the increase in the pore diameter. 


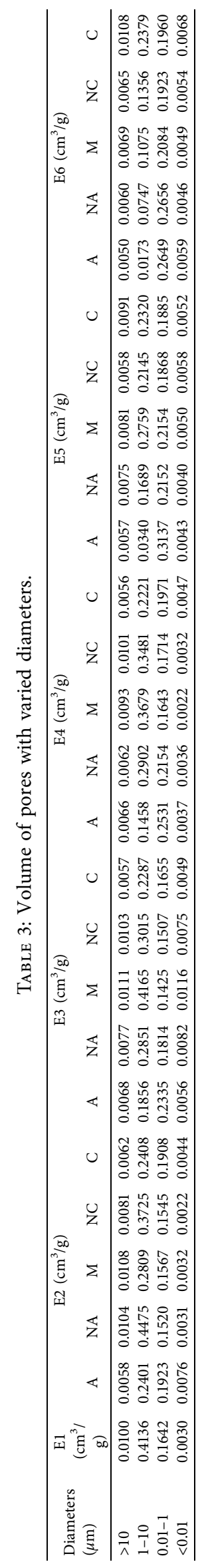




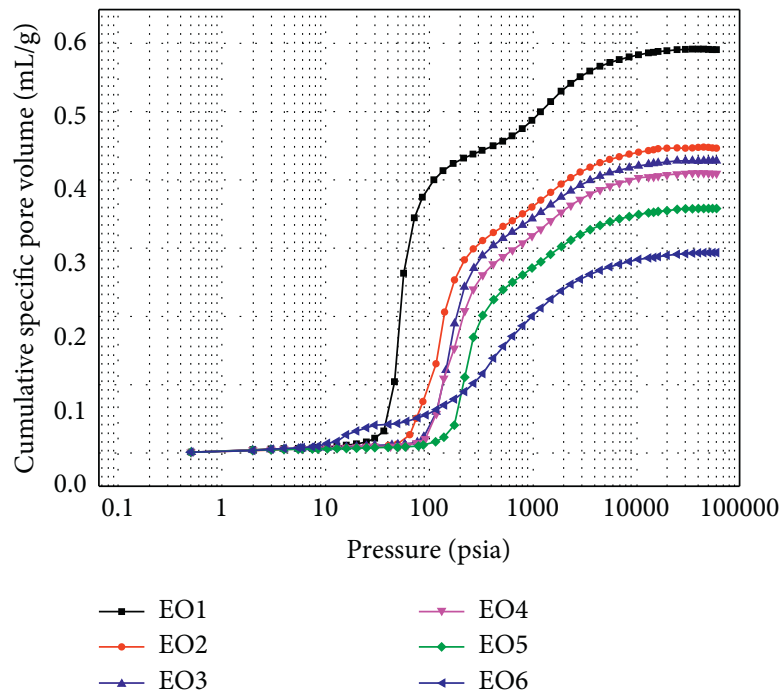

FIGURE 8: Total pore volume in anode soils.
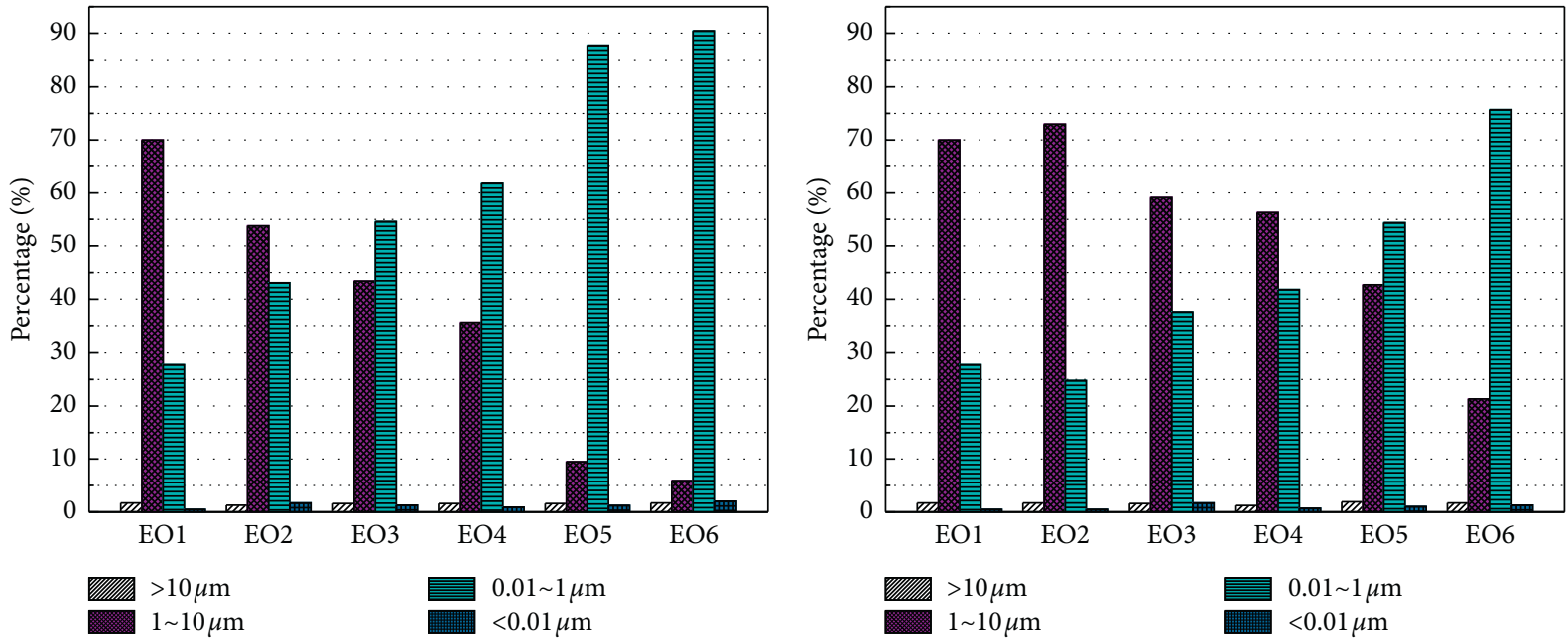

(a)
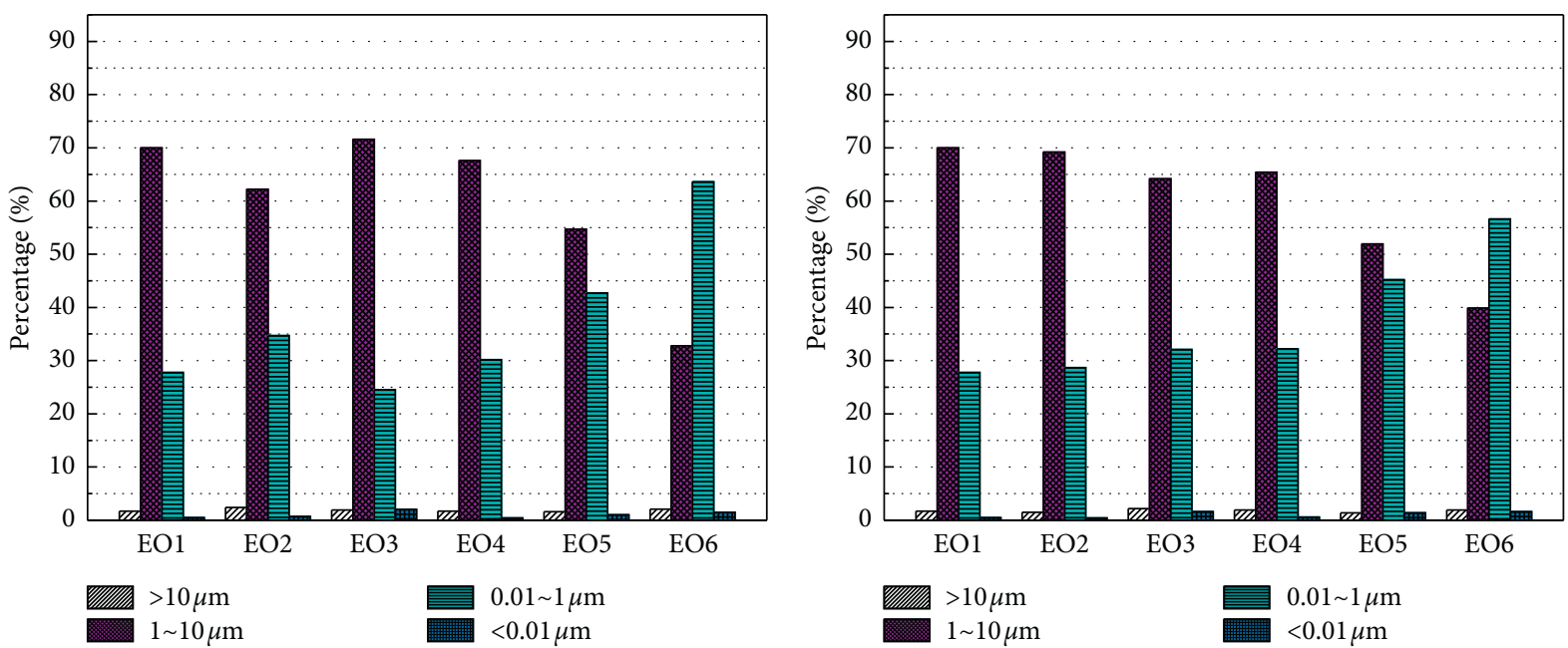

(c)

(d)

FIgURE 9: Continued. 


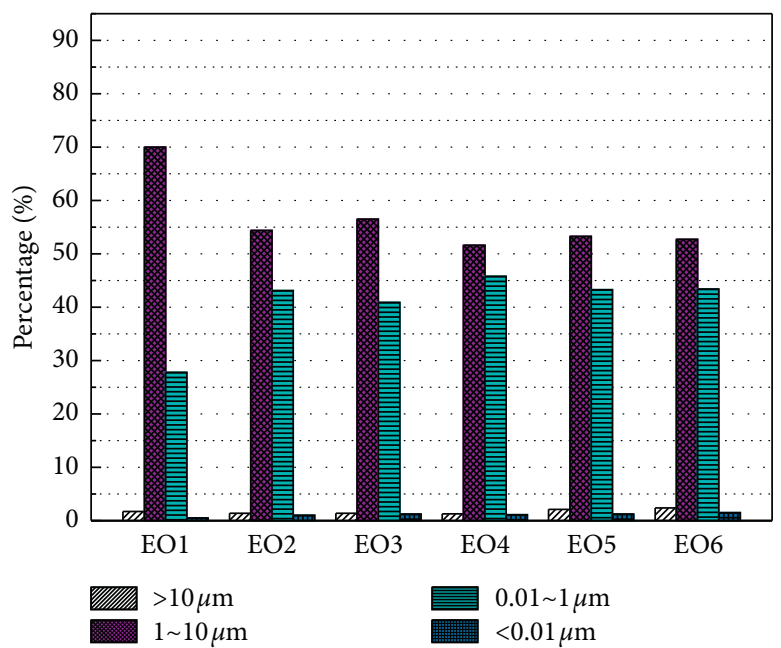

(e)

Figure 9: Volume percentage of different pore diameters. (a) Anode. (b) Near anode. (c) Middle. (d) Near cathode. (e) Cathode.

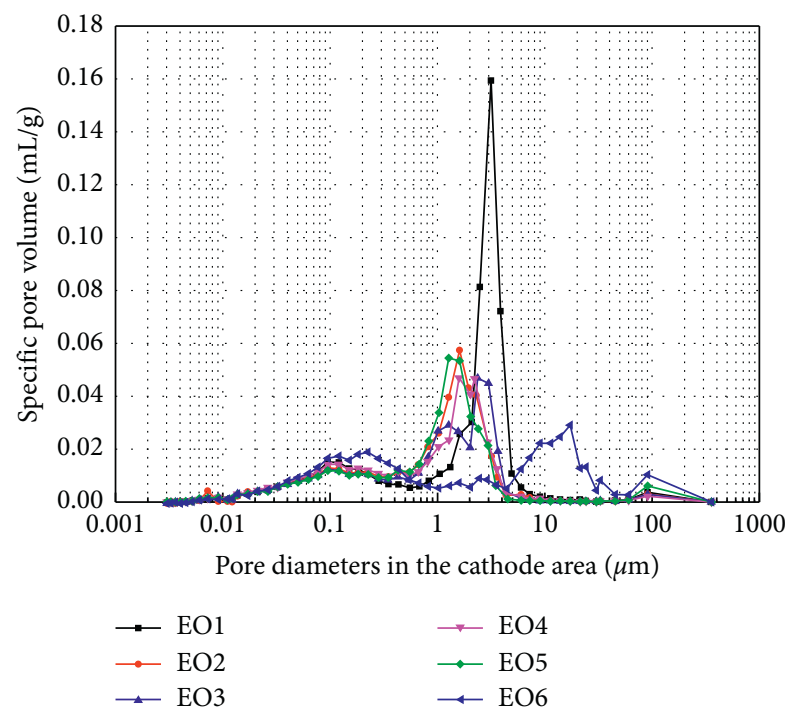

Figure 10: Pore diameters in the cathode area.

Figure 9 shows the proportions of pores with a diameter of $0.01-1 \mu \mathrm{m}$ and $1-10 \mu \mathrm{m}$ in anodic and cathodic soil. The variations in pores with a diameter between 0.01 and $1 \mu \mathrm{m}$ and between 1 and $10 \mu \mathrm{m}$ in cathodic soil are relatively small compared with those of anodic soil, $27.8 \%$ to $43.4 \%$ and $70.0 \%$ to $52.7 \%$ before and after treatment, respectively. It is noticeable that the proportion varies little between $\mathrm{EO} 3$ and EO6, which shows high consistency with the moisture content. Pore size is strongly related to the water content in the cathode area when the moisture content is higher than the liquid limit.

The difference between anode and cathode soil can be driven by the uneven distribution of moisture content. As stated above, once the soil's water content is higher than its liquid limit (53.1\%), soil's shear strength is zero. Anodic soil's water content fell below the liquid limit after EO2, and the proportions of pores with a diameter of $0.01-1$ and

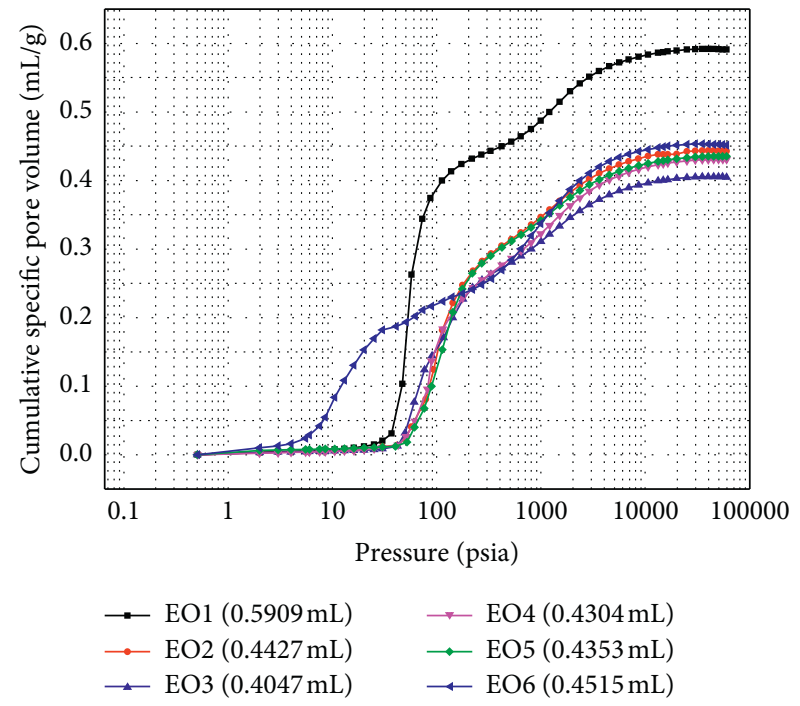

Figure 11: Total pore volume in cathode soils.

1-10 $\mu \mathrm{m}$ changed along with the treating process. Conversely, the moisture content for cathodic soil remained higher than the liquid limit through the whole process. As a result, the proportion changes were relatively small. Similar facts are found in the NA, M, and NC samples. Water contents fell below the liquid limit between $\mathrm{EO} 3$ and $\mathrm{EO} 4$ for $\mathrm{NA}$ samples, and between EO4 and EO5 for M and NC samples. The proportions of the two pore diameters began to change distinctly once the moisture content was lower than the liquid limit as shown in Figure 11, because when the moisture content is higher than the liquid limit, no structural stress exists among the soils, and the intervals among the soil aggregates are linked and filled with pore water. The soil can be seen as "floating" in the water, but when the moisture content drops below the liquid limit, soil aggregates begin to touch each other, and the weak structural aggregates start to collapse under the matric suction. 


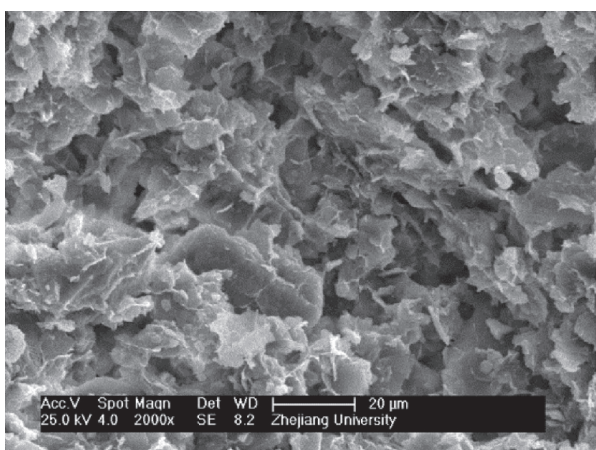

(a)

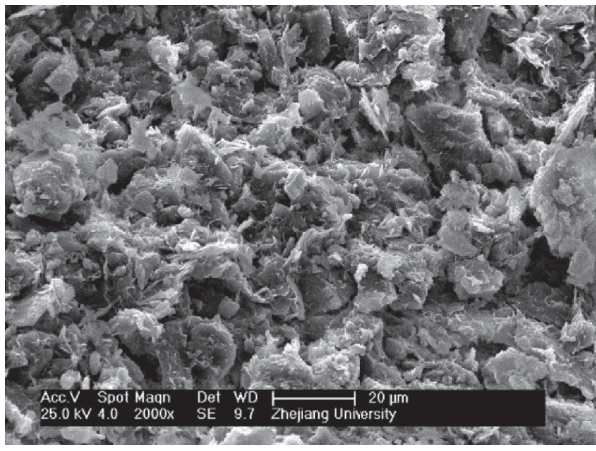

(c)

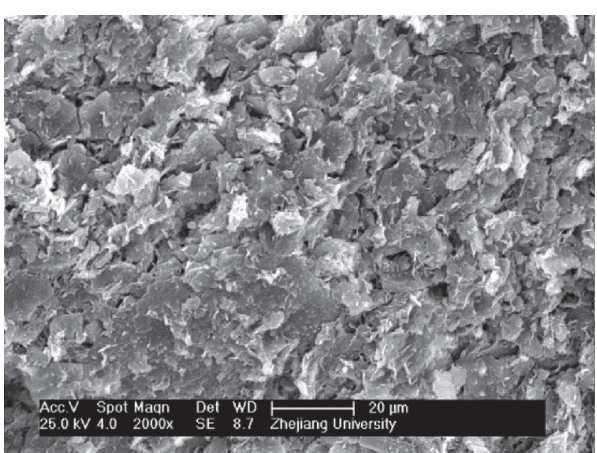

(b)

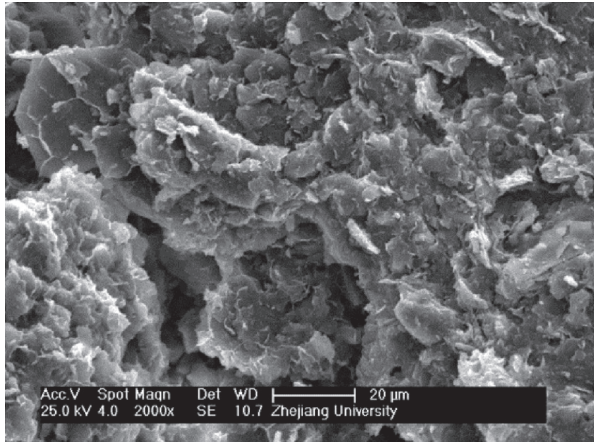

(d)

Figure 12: SEM images. (a) Soil before treatment. (b) Anode soil after treatment. (c) Middle soil after treatment. (d) Cathode soil after treatment.

TABLE 4: Microstructural characteristic data of the samples.

\begin{tabular}{lcccc}
\hline Number & Average area $\left(\mu \mathrm{m}^{2}\right)$ & Average perimeter $(\mu \mathrm{m})$ & Roundness & Feret angle \\
\hline a) & 0.043 & 0.686 & 0.888 & 35.109 \\
b) & 0.025 & 0.532 & 0.868 & 34.903 \\
c) & 0.033 & 0.551 & 0.899 & 35.582 \\
d) & 0.052 & 0.712 & 0.901 & 36.938 \\
\hline
\end{tabular}

3.3. SEM. The surface characteristics and clay particle connections were observed through SEM before and after the treatment. The typical SEM images of a magnification of 2000 times in A, M, and C samples are displayed in Figure 12. The images represent the lateral feature of the soil surfaces, and the quantitative microstructural characteristic data are summarized in Table 4 . The statistical analysis of the image data has been proved to be effective and applicable [35-37].

In Figure 12(a), the soil aggregates are connected to each other edge-to-edge or edge-to-face and exhibit a flocculated and card-house structure. Pores with large diameters are clearly visible throughout the soil, and the orientation angles of the soil particles are evenly distributed in all directions.

In anodic soils, as shown in Figure 12(b), after the treatment, large-diameter pores nearly vanish in the image. There are only small pores between clays and aggregates. Meanwhile, the connections between soil aggregates become face-to-face, forming a laminated structure and an even tighter soil layer. This shows that EO treatment is capable of improving the stressstrain characteristics and reducing the sensitivity of the soil, as
Talu [38] mentioned. In the middle soil, as Figure 12(c) illustrates, pores are smaller than the cathodic soil but larger than the anodic soils; this can be seen as a median between cathodic and anodic soil. Figure 12(d) illustrates the surface features of the cathodic soil after treatment. The large-diameter pores are still visible after the process, which is in agreement with the test results in the MIP tests. However, no noticeable change in the orientation angles was observed in any sample. This leads to the conclusion that, under the negative pore pressure generated by the electric voltage, the plane geometry arrangement alters very little. Li [39] explained that because no actual stress was applied on the soil layers, large pore fracturing is simply a consequence of pore water discharge and matric suction. Both aspects cause a collapse of the soil structure without influencing the soil aggregate orientation.

\section{Conclusion}

This paper investigates the microscopic characteristics of soil during the electroosmosis dewatering process using laboratory experiments, scanning electron microscopy, and mercury 
intrusion porosimetry. From the discussion above, we could conclude that EO tests reveal that moisture content distribution during the treatment process is highly related to the distance from the drainage outlets and the treatment duration. It is notable that the water content in the cathodic soil drops in the early stage but increases later in the EO treatment period.

In the SEM tests, the soil aggregate micromorphology changed due to the pore water discharge and matric suction. More intense soil layers were observed after the process in the anodic soil, but only a slight change was observed in the cathodic soil. MIP test results indicate that EO treatment could influence the proportion of pores with different diameters, mainly $0.01-1 \mu \mathrm{m}$ and $1-10 \mu \mathrm{m}$. Their proportions start to change when the moisture content is less than the liquid limit. The total volume of the pores varied $48.54 \%$ after the first $20 \%$ of the drained water was exported in anodic soil, showing that the pore volume is not linearly related to the amount of drained water.

\section{Data Availability}

All the data in the text are obtained through indoor experiments, which were conducted by the authors themselves.

\section{Conflicts of Interest}

The authors declare that they have no conflicts of interest.

\section{References}

[1] H.-L. Liu, Y.-L. Cui, Y. Shen, and X.-m. Ding, "A new method of combination of electroosmosis, vacuum and surcharge preloading for soft ground improvement," China Ocean Engineering, vol. 28, no. 4, p. 511, 2014.

[2] Y. Shen, Y.-D. Li, W.-J. Huang, H.-D. Xu, and P.-F. Hu, "Vertical drainage capacity of new electrical drainage board on improvement of super soft clayey ground," Journal of Central South University, vol. 22, p. 4027, 2015.

[3] L. Cassagrand, "Electro-osmosis in soils," Journal of Boston Society of Civil Engineers, vol. 39, p. 51, 1952.

[4] F. Burnotte, G. Lefebvre, and G. Grondin, "A case record of electroosmotic consolidation of soft clay with improved soil-electrode contact," Canadian Geotechnical Journal, vol. 41, no. 6, p. 1038, 2004.

[5] V. Milligan, "First application of electro-osmosis to improve the friction pile capacity - three decades later. (Paper presented at the 13Th international conference on soil mechanics \& foundation engineering, New Delhi, early 1994)," Proceedings of the Institution of Civil Engineers - Geotechnical Engineering, vol. 113, no. 2, p. 112, 1995.

[6] E. Mohamedelhassan and J. Q. Shang, "Effects of electrode materials and current intermittence in electro-osmosis," Proceedings of the Institution of Civil Engineers - Ground Improvement, vol. 5, no. 1, p. 3, 2001.

[7] S. Glendinning, J. Lamont-Black, C. J. F. P. Jones, and J. Hall, "Treatment of lagooned sewage sludge in situ using electrokinetic geosynthetics," Geosynthetics International, vol. 15, no. 3, p. 192, 2008.

[8] D. Kalumba, S. Glendinning, C. D. F. Rogers, M. Tyrer, and D. I. Boardman, "Dewatering of tunneling slurry waste using electrokinetic geosynthetics," Journal of Environmental Engineering, vol. 135, no. 11, p. 1227, 2009.
[9] S. Micic, J. Q. Shang, K. Y. Lo, Y. N. Lee, and S. W. Lee, "Electrokinetic strengthening of a marine sediment using intermittent current," Canadian Geotechnical Journal, vol. 38, no. 2, p. 287, 2001.

[10] D. Jiao, X.-N. Gong, and Y. Li, "Experimental study of consolidation of soft clay using electro-osmosis method," Chinese Journal of Rock Mechanics and Engineering, vol. 30, p. 3208, 2011.

[11] J. Q. Shang, "Electrokinetic sedimentation: a theoretical and experimental study," Canadian Geotechnical Journal, vol. 34, no. 2, p. 305, 1997.

[12] P. Asavadorndeja and U. Glawe, "Electrokinetic strengthening of soft clay using the anode depolarization method," Bulletin of Engineering Geology and the Environment, vol. 64, no. 3, p. 237, 2005.

[13] Z. Yu, Y. Zhang, B. Zhou, L. Guo, Z. Li, and X. Li, "Laboratory investigation of electro-osmosis effects in saturated dredger fill-a comparison with the stack preloading," Drying Technology, vol. 35, no. 6, p. 736, 2017.

[14] J. Wang, H.-T. Fu, Y.-Q. Cai, F.-J. Zeng, and J.-J. Shen, "Analysis of one dimensional electro-osmotic consolidation theory and test of soft clay under linear load," Chinese Journal of Rock Mechanics and Engineering, vol. 33, p. 179, 2014.

[15] C.-Y. Ou, S.-C. Chien, and Y.-G. Wang, "On the enhancement of electroosmotic soil improvement by the injection of saline solutions," Applied Clay Science, vol. 44, no. 1-2, p. 130, 2009.

[16] J. Q. Shang, "Electroosmosis-enhanced preloading consolidation via vertical drains," Canadian Geotechnical Journal, vol. 35, no. 3, p. 491, 1998.

[17] L. $\mathrm{Hu}, \mathrm{W}$. Wu, and $\mathrm{H}$. Wu, "Numerical model of electroosmotic consolidation in clay," Géotechnique, vol. 62, no. 6, p. 537, 2012.

[18] J.-Q. Su and Z. Wang, "Theory of two-dimensional electroosmosis consolidation of soils," Rock Mechanics, vol. 25, p. 125, 2004.

[19] Y.-F. Zhuang and Z. Wang, "Electric charge accumulation theory for electro-osmotic consolidation," Rock Mechanics, vol. 26, p. 629, 2005.

[20] J. Yuan and M. Hicks, "Influence of gas generation in electroosmosis consolidation," International Journal for Numerical and Analytical Methods in Geomechanics, vol. 36, p. 1, 2016.

[21] C. Tamagnini, C. Jommi, and F. Cattaneo, "A model for coupled electro-hydro-mechanical processes in fine grained soils accounting for gas generation and transport," Anais da Academia Brasileira de Ciências, vol. 82, no. 1, p. 169, 2010.

[22] E. D. Mattson, R. S. Bowman, and E. R. Lindgren, "Electrokinetic ion transport through unsaturated soil: 1. Theory, model development, and testing," Journal of Contaminant Hydrology, vol. 54, no. 1-2, p. 99, 2002.

[23] J. Yuan and M. A. Hicks, "Large deformation elastic electroosmosis consolidation of clays," Computers and Geotechnics, vol. 54, p. 60, 2013.

[24] Y. Zhou, A. Deng, and C. Wang, "Finite-difference model for one-dimensional electro-osmotic consolidation," Computers and Geotechnics, vol. 54, p. 152, 2013.

[25] H. Xu and T. Ding, "Influence of vacuum pressure, $\mathrm{pH}$, and potential gradient on the vacuum electro-osmosis dewatering of drinking water treatment sludge," Drying Technology, vol. 34, no. 9, p. 1107, 2016.

[26] W.-Y. Li and M.-Y. Jiang, "Experimental research on electrochemical modification of expansive soil," Journal of Yangtze River Scientific Research Institute's, vol. 34, p. 1, 2017. 
[27] V. Jeyakanthan, C. T. Gnanendran, and S.-C. R. Lo, "Laboratory assessment of electro-osmotic stabilization of soft clay," Canadian Geotechnical Journal, vol. 48, no. 12, p. 1788, 2011.

[28] S. Diamond, C. W. Lovell, and S. Ahmed, "Pore sizes and strength of compacted clay," J. Geotech. Geoenviron Eng, vol. 100, p. 24, 1974.

[29] S.-X. Chai, W.-F. Han, P. Wang, and H.-Z. Wei, "Experiment on artificially-prepared clay samples by freeze-drying for SEM," Coal Geology and Exploration, vol. 33, p. 46, 2005.

[30] E. W. Washburn, "Note on a method of determining the distribution of pore sizes in a porous material," Proceedings of the National Academy of Sciences, vol. 7, no. 4, p. 115, 1921.

[31] Y.-L. Tao, J. Zhou, and X.-N. Gong, "Experimental study on function mechanism of electrode materials upon electro-osmotic process," Journal of Zhejiang University, vol. 48, p. 1618, 2014.

[32] F.-Y. Liu, L. Zhang, J. Wang, and B. Zhang, "Experimental analysis of the electro-osmosis consolidation of soft clay under anode follow-up," Journal of Civil and Environmental Engineering, vol. 36, p. 52, 2014.

[33] F. J. Griffiths and R. C. Joshi, "Change in pore size distribution due to consolidation of clays," Géotechnique, vol. 39, no. 1, p. $159,1989$.

[34] M. I. Esrig, "Pore pressure, consolidation and electrokinetic," Journal of the Soil Mechanics and Foundations Division, vol. 94, p. 899, 1968.

[35] D. Sobola, S. Ramazanov, M. Konečný et al., "Complementary SEM-AFM of swelling Bi-Fe-O film on Hopg substrate," Materials, vol. 13, no. 10, p. 2402, 2020.

[36] Ş. Ţălu, R. Dallaev, and D. Sobola, "Evaluation of surface characteristics of highly oriented pyrolitic graphite," in Proceedings of 2018 2nd International Conference on Advances in Management Science and Engineering(AMSE 2018), pp. 161165, DEStech Publications, June 2018.

[37] D. Sobola, P. Kaspar, P. Tofel, and V. Holcman, "Scanning electron microscopy and energy-dispersive $\mathrm{X}$-ray spectroscopy analysis of electrochemically etched graphite tips created from pencil lead," Microscopy Research and Technique, vol. 83, no. 2, pp. 196-201, 2020.

[38] Ş. Țalu, Micro and Nanoscale Characterization of Three Dimensional Surfaces. Basics and Applications, Napoca Star Publishing House, Cluj-Napoca, Romania, 2015.

[39] X. Li, L.-M. Zhang, and G.-D. Ao, "Variations of pore structure, void ratio, and water content in soil drying process," Rock Soil Mechanics, vol. 32, p. 100, 2011. 